\title{
Current Oral Contraceptive User
}

National Cancer Institute

\section{Source}

National Cancer Institute. Current Oral Contraceptive User. NCI Thesaurus. Code C157411.

An indication that an individual currently uses oral contraceptives. 